\title{
Anxiety, depression, traumatic stress and quality of life in colorectal cancer after different treatments: A study with Portuguese patients and their partners
}

\author{
M. Graça Pereira ${ }^{\mathrm{a}, *}$, Ana Paula Figueiredo ${ }^{\mathrm{b}}$, Frank D. Fincham ${ }^{\mathrm{c}}$ \\ ${ }^{a}$ University of Minho, School of Psychology, Campus of Gualtar, 4710-057 Braga, Portugal \\ ${ }^{\mathrm{b}}$ Instituto Português de Oncologia do Porto, Portugal \\ ${ }^{\mathrm{c}}$ Florida State University, Portugal
}

Keywords:

Colorectal cancer

Partners

Depression

Anxiety

Traumatic stress

Quality of life

\begin{abstract}
A B S T R A C T
Purpose: This study examines the impact of different modes of treatment on depression, anxiety, traumatic stress and quality of life in colorectal cancer patients and their partners.

Methods: The sample was comprised of 114 oncology patients and 67 partners. All patients were diagnosed with colorectal cancer. Participants were recruited from an Oncology Hospital in the North of Portugal and had been submitted to three modes of treatment: surgery, surgery plus chemotherapy or surgery followed by radiotherapy.

Results: The results showed that patients who received only surgery, as treatment, had lower levels of depression, anxiety and traumatic stress symptoms when compared with patients who received surgery and chemotherapy or surgery plus radiotherapy. Partners of surgical patients presented lower levels of state anxiety and traumatic stress symptoms when compared with the other two groups. Patients with more depression had partners also more depressed. No relationship was found between anxiety and traumatic stress symptoms in patients and partners. Patients who received a diagnosis longer than 12 months had more traumatic stress, intrusion and hypervigilance. Patients with illness recurrence showed more traumatic symptoms. Anxiety and depression were the main predictors of patient's quality of life. Traumatic stress was a predictor of symptom distress - pain/bowel pattern.

Conclusion: This study highlights the importance of providing psychological interventions for cancer patients and their partners. Chemotherapy patients and those diagnosed over a year, as well as their partners, are more at risk.
\end{abstract}

(c) 2011 Elsevier Ltd. All rights reserved.

\section{Introduction}

Colorectal cancer is the second leading cause of cancer mortality in Western countries. Both sexes are equally affected by this disease, however there is a higher incidence in people over fifty years. In Portugal, according to the National Oncology Register (Pontes, 2005), the incidence of colon and rectum cancer is $33,4 \%$ for females and $42,8 \%$ for males.

Many studies have linked colorectal cancer to economic conditions, geographical location and diet (Imbembo and Lefour, 1993; Belcher, 1996). Cancer often requires invasive treatments that may affect body image, sexuality, physical and psychological wellbeing (McCray, 2000; Wagner and Cella, 2004) and, consequently, quality of life. The treatment of choice for colon and rectum cancer is surgery (Ganzl, 1996; Santos, 1999; Murphy, 2000). Surgery,

\footnotetext{
* Corresponding author. Tel.: +351 253 604228; fax: +351 2536042224

E-mail address: gracep@psi.uminho.pt (M. Graça Pereira).
}

radiation therapy and chemotherapy are used to cure, prolong life and to palliate symptoms in cancer patients. The hematological malignancies and lympho-prolifaretive disorders are treated with chemotherapy while in solid tumors, chemotherapy is used either as adjuvant or neoadjuvant (Pandey et al., 2006). Chemotherapy and radiation treatments have an impact on patient's quality of life due to treatments' secondary effects (Couvreur, 2001; Hann et al., 1998; Smith and Tchekmedyian, 2002) that can cause short and long-term adverse effects resulting in health deterioration (Yost et al., 2008).

Chronic illness not only affects the patient but also the couple (Pereira and Lopes, 2002; Figueiredo et al., 2001; Santos, 1999). Weihs and Reiss (1996) reported that insecure couple relationships are more vulnerable to the effects of cancer when compared to safe relationships that serve as a shield from the destructive impact of cancer. Patient and partner go through a mourning process when faced with cancer (Maden, 2006; Lopes, 1997). Some studies document psychological morbidity and post-traumatic stress in both cancer patients and their partners. Depression in patients is 
14-24\% higher than in the general population (Potash and Breibart, 2002). In fact, $29 \%-43 \%$ of cancer survivors with 14 different types of cancer diagnosis have subclinical or clinical depression (Zabora et al., 2001) and about 20\%-25\% experience major depressive disorder. Patients with depression associated to cancer are at risk for poorer health outcomes than those with cancer alone (Zabora et al., 2001).

Maguire (1994) believes that anxiety and depressive symptoms in partners are a result of the uncertainties related to cancer prognosis and the possibility of death. For Bishop (1994) and Weitzner et al. (1999), the impact of cancer in partners is associated to stress and depression, with a magnitude equal or greater than in patients. In fact, $25 \%$ of partners, often suffer the same or higher levels of emotional distress as cancer survivors (Badger et al., 2007). Blanchard et al. (1997) reported that the percentage of partners who present mood disturbances and psychological deterioration ranges from 20 to 30\% compared to cancer patients.

Cancer has certain features that may contribute to the development of post-traumatic stress disorder (PTSD). In fact, the diagnosis, treatments with adverse side effects, follow-up exams and the possibility of relapse, require the patient and partner to be continually exposed to memories of the life threatening nature of the disease and its symptoms (Passik and Grummon, 1998; Potash and Breibart, 2002). Cancer is associated with a threat to physical integrity and its sudden, unpredictable, often irreversible features are associated to a loss of an healthy identity, significant factors that may contribute to post-traumatic stress disorder (Andrykowski and Cordova, 1998; Perez and Galdón, 2002). PTSD symptoms can arise at various stages of the disease including diagnosis (Roth and Breitbart, 2001).

Different types of treatment have a different impact on patients. Surgical treatments are often associated with mutilation, particularly if important organs are involved like the intestinal organ (Gaecia et al., 1996; Santos, 1999). The possible loss of autonomy, often associated with the feeling of burden, disrupts patient's quality of life (Santos, 1995; Demetri, 2001; Hurter and Bush, 2007). Several studies have assessed the impact of different treatments on patient's quality of life (Schmidt et al., 2005; Pollack et al., 2006). Patients going through radiotherapy reported having more pain than non-radiated patients. Those patients who received chemotherapy presented problems on cognitive function, pain and appetite loss that were associated to type of protocol received (Nicolussi and Sawada, 2009).

In light of the above considerations, this paper assesses the influence of treatment (i.e. surgery; surgery and chemotherapy; surgery and radiotherapy) in patients with colorectal cancer and their partners, on quality of life, depression, anxiety and traumatic stress symptoms. The authors hypothesized that there would be differences among the three groups, in both patients and partners, expecting the group that received only surgery to have lower levels of psychological morbidity in all three measures when compared to other treatment modalities. The authors also predict a positive relationship between psychological morbidity (depression, anxiety and traumatic stress symptoms) in patients and partners regardless of patients' treatment. Finally, the authors were interested in finding out the best predictors of self reported quality of life in patients.

\section{Methodology}

\section{Sample}

141 patients ( $62 \%$ males and $38 \%$ females) and 67 partners (39\% males and $61 \%$ females) participated in the study. All patients were diagnosed with colorectal cancer. Participants were recruited from a central Oncology Hospital in the North of Portugal. Patients were divided in three groups: Group A included 35 patients who received only surgical treatment and 19 partners; group B consisted of 41 patients who received treatment of surgery followed by chemotherapy and 26 partners; group C included 38 patients who received surgery followed by radiotherapy and 22 partners.

$42 \%$ of patients and $28 \%$ of partners had finished primary school, $22 \%$ of patients and $6 \%$ of partners had finished high school. Only $18 \%$ of patients and $22 \%$ of partners had more than 9 years of schooling. Only $9 \%$ of patients were active.

$48 \%$ of patients had received a cancer diagnosis longer than a year and $29 \%$ received treatment for cancer recurrence.

\section{Procedure}

During the period of 12 months, after receiving the list of patients who underwent chemotherapy, radiotherapy or surgery, one of the authors invited patients and partners to participate in the study when they visited, during that year, the physician for their regular hospital follow-up appointments. Patients and partners, who agreed to participate, completed questionnaires in separate rooms after filling the informed consent. Due to the fact that some patients had no partners, there was a significant difference in the number of partners and patients in the study. In addition, partners with cancer were excluded from the study.

\section{Instruments}

\section{Patients}

Anxiety and depression were assessed by the Hospital Anxiety and Depression Scale (HADS), (Zigmond \& Snaith, 1983). The scale has 14 items. Reliability for the adapted version (Pereira and Figueiredo, 2008) is 0.94 . The anxiety subscale has an alpha of .91 and the depression subscale an alpha of 0.88 . Cut off scores for clinical depression in cancer patients has been set at 5 , clinical anxiety at 7 and psychological morbidity (total scale) at 13 (Singer et al., 2009). Higher scores indicate higher morbidity.

Quality of life was assessed with the Quality of Life Scale- Cancer (QOL-CA2), (Padilla et al., 1983). QOL-CA has 30 items and five subscales: Existential Well-Being, Physical Functional Well-Being, Symptoms Distress-Nutrition, Attitude of Worry and Symptom Distress-Pain/Bowel Pattern. Reliability for the Portuguese version (Pereira and Figueiredo, 2005) was 0.94 for the total scale and the alpha ranged from 0.80 to 0.90 for subscales except for the subscale "attitude of worry" that had an alpha of 0.66 but due to the fact that has only three items, it is considered acceptable (Nunnally, 1978). High scores indicate less quality of life.

\section{Partners}

Due to the fact that HADS was not adapted in non-clinical Portuguese samples, depression was assessed with the Beck Depression Inventory (BDI), (Beck et al., 1961). The scale includes 20 items. Reliability for the Portuguese adapted version (McIntyre and McIntyre, 1995a) is 0.89. In the Portuguese version, cut off scores have been set by Gouveia (1990) at: 0 to 9 (absence of depression), 10 to 30 (moderately depressed) and above 30 (severely depressed). Higher scores indicate more depression.

Anxiety was evaluated with the State Trait Anxiety Inventory (STAI), (Spielberger et al., 1983). The scale has 40 items, 20 for state anxiety and 20 for trait anxiety. The Portuguese Version (McIntyre and McIntyre, 1995b) showed an alpha of 0.79 for Trait Anxiety and 0.94 for State Anxiety. A mean score above 35.2 , for active adults, is 
considered clinical anxiety (Spielberger et al., 1983). Higher scores indicate more anxiety.

Finally, patients and partners completed the Impact of Events Scale Revised (IES-R), (Weiss \& Marmer, 1977). The scale has 22 items. A cut off score of 33 indicates probable PTSD (Creamer et al., 2003). The Portuguese adapted version (Pereira and Figueiredo, 2008) for patients showed a reliability of 0.90 (total scale), for the subscale "Intrusion" an alpha of 0.91 , for "Hypervigilance" 0.89 and, finally, for "Avoidance" 0.70 . In partners, reliability for the total instrument was 0.90 , and for Intrusion 0.90, for Hypervigilance, 0.82 and, finally, for Avoidance 0.75 . Higher scores indicate more traumatic symptoms.

\section{Data analysis}

Differences among groups were tested using MANOVA and, when appropriate, Scheffé tests were performed. Listwise deletion was used for the analysis that included both patients and partners to ensure that there would be equal numbers. The relationship between depression, anxiety and PTSD in patients and partners was analyzed using Pearson correlations. Differences among patients, according to diagnosis duration and cancer recurrence, were assessed by Manova in the first case and a $t$ test in the second since the corollaries for parametric statistics were present (the distribution was normal and variance was controlled assuming unequal variances among the groups in both tests). Regression analysis was used to determine the predictors of quality of life (stepwise method). The variables included in the model were anxiety, depression and traumatic stress symptoms since they were all correlated with quality of life (dependent variable).

\section{Results}

Differences in anxiety, depression and post-traumatic stress symptoms in patients and partners according to treatment

The results showed significant differences in anxiety, depression and traumatic stress symptoms among the three groups (Table 1). Scheffé tests showed that patients who undergone surgery/ chemotherapy had more anxiety $(p \leq 0.001)$, more depression $(p \leq 0.005)$ and more traumatic symptoms $(p \leq 0.001)$ when compared to the surgical group. Patients who went through surgery/radiotherapy, compared to surgical patients, presented more anxiety $(p \leq 0.006)$, more depressive symptoms $(p \leq 0.041)$ and more traumatic symptoms $(p \leq 0.001)$. No differences were found between the groups surgery/chemotherapy and surgery/ radiotherapy in all three measures.

Table 1

Results of Manova in patients with colorectal cancer $(n=141)$ and partners $(n=67)$ according to treatment.

\begin{tabular}{|c|c|c|c|c|c|}
\hline Patients & $\begin{array}{l}\text { Surgery } \\
\text { mean } \\
(n=35)\end{array}$ & $\begin{array}{l}\text { Surgery/ } \\
\text { Chemotherapy } \\
\text { mean }(n=41)\end{array}$ & $\begin{array}{l}\text { Surgery/ } \\
\text { Radiotherapy } \\
\text { mean }(n=38)\end{array}$ & $F$ & $p$ \\
\hline Anxiety (HADS) & 5,97 & 10,41 & 9,73 & 8,57 & $<0.001$ \\
\hline Depression (HADS) & 5,42 & 9,02 & 8,26 & 5,93 & 0.004 \\
\hline $\begin{array}{l}\text { Traumatic Stress } \\
\quad(\text { IES-R) }\end{array}$ & 6,92 & 8,80 & 8,62 & 12,76 & $<0.001$ \\
\hline Partners & $(n=19)$ & $(n=26)$ & $(n=22)$ & $F$ & $p$ \\
\hline $\begin{array}{r}\text { State Trait Anxiety } \\
\text { Inventory (STAI) }\end{array}$ & 40,68 & 44,36 & 42,95 & 1,13 & 0.329 \\
\hline $\begin{array}{l}\text { State Trait Anxiety } \\
\text { Inventory (STAI) }\end{array}$ & 42,68 & 54,61 & 50,04 & 4,69 & 0.012 \\
\hline Depression (BDI) & 10,47 & 13,61 & 10,81 & 0,98 & \\
\hline $\begin{array}{l}\text { Traumatic Stress } \\
\text { (IES-R) }\end{array}$ & 7,00 & 8,59 & 8,07 & 3,83 & 0.027 \\
\hline
\end{tabular}

In partners, the results showed significant changes in anxiety (state) and traumatic stress symptoms according to treatment. Partners of surgical patients presented lower levels of state anxiety and traumatic stress when compared with partners of the other two groups. Scheffé tests revealed that surgical patients had significant less anxiety $(p<0.013)$ and traumatic stress $(p<0.028)$ than the surgery/chemotherapy group. No differences were found in partners of patients who received surgery/radiotherapy compared to partners of patients who received surgery/chemotherapy. Table 1 shows the results for both patients and partners.

\section{Differences in traumatic stress symptoms according to diagnosis duration and recurrence}

A significant difference on global traumatic stress was found in patients according to diagnosis duration. Patients with a diagnosis over a year presented more global traumatic stress, intrusion and hypervigilance. Scheffé tests showed that this group (group 1) had more traumatic stress than those with less than a six months diagnosis $(p<0.006)$ (group 3 ) and also from those with a diagnosis between six months and a year (group 2), $(p<0.004)$. In terms of traumatic stress clusters, group 3 had more avoidance than group $1(p<0.002)$ and $2(p<0.016)$ but less intrusion than group $1(p<0.001)$ and $2(p<0.001)$ as well as less hypervigilance than group $1(p<0.001)$ and $2(p<0.004)$. Table 2 shows the results.

$29 \%$ of patients reported they had received treatment for a cancer recurrence. Significant differences were found in traumatic stress between the group of patients with recurrence versus no recurrence with the first one showing more traumatic stress that the other group $(t=7.14, p<0.001)$. No differences were found in traumatic stress, in the recurrence group, by type of treatment.

Regarding depression and anxiety no differences were found in the two groups.

\section{Relationship between depression, anxiety and PTSD in patients and partners}

Results showed that the only significant variable that was associated in patients and partners was depression $(r=0.287$; $p=0.021$ ). Depressed patients seem to have depressed partners and vice-versa. No differences were found on anxiety and traumatic stress between patients and partners.

\section{Predictors of quality of life}

Anxiety and depression predicted overall quality of life, explaining $78.4 \%$ of variance. In terms of quality of life domains: anxiety and depression predicted psychosocial existential wellbeing explaining $63,6 \%$ of variance and physical functional wellbeing explaining $76.7 \%$ of the variance.

Anxiety alone predicted symptoms distress-nutrition and attitude of worry, explaining respectively, $27.6 \%$ and $43.6 \%$ of the variance. Finally, traumatic stress and anxiety together predicted symptoms distress - paid bowel pattern, explaining $51 \%$ of the variance. Table 3 shows the results.

Table 2

Results of Manova on PTSD in patients according to Diagnosis duration ( $n=141)$.

\begin{tabular}{|c|c|c|c|c|c|}
\hline \multirow[t]{2}{*}{ Post-traumatic stress } & \multicolumn{3}{|l|}{ Means } & \multirow[t]{2}{*}{$F$} & \multirow[t]{2}{*}{$p$} \\
\hline & $\begin{array}{l}<6 \text { months } \\
(n=31)\end{array}$ & $\begin{array}{l}6 \text { months to } \\
1 \text { year }(n=29)\end{array}$ & $\begin{array}{l}>1 \text { year } \\
(n=54)\end{array}$ & & \\
\hline IES-R & 7,54 & 7,47 & 8,16 & 8173 & $<0.001$ \\
\hline IES-R - Avoidance & 3,09 & 2,41 & 2,60 & 7030 & 0.001 \\
\hline IES-R - Intrusion & 2,33 & 2,54 & 3,20 & 15,461 & $<0.001$ \\
\hline IES-R - Hypervigilance & 2,11 & 2,51 & 3,07 & 10,59 & $<0.001$ \\
\hline
\end{tabular}


Table 3

Predictors of quality of life $(n=141)$.

\begin{tabular}{|c|c|c|c|c|c|c|}
\hline & \multicolumn{6}{|c|}{ Standardized betas } \\
\hline & $\begin{array}{l}\text { Total Quality } \\
\text { of life }\end{array}$ & $\begin{array}{l}\text { Quality of life: Psychosocial } \\
\text { existential well-being }\end{array}$ & $\begin{array}{l}\text { Quality of life: Physical } \\
\text { functional well-being }\end{array}$ & $\begin{array}{l}\text { Quality of Life: Symptom } \\
\text { distress - nutrition }\end{array}$ & $\begin{array}{l}\text { Quality of Life: Symptom } \\
\text { distress - pain/bowel pattern }\end{array}$ & $\begin{array}{l}\text { Quality of life: Attitude } \\
\text { of worry }\end{array}$ \\
\hline Anxiety & $0.472^{* * *}$ & $0.449^{* * *}$ & $0.662^{* * *}$ & $0.525^{* * *}$ & $0.514^{* * *}$ & $0.661^{* * *}$ \\
\hline Depression & $0.454^{* * *}$ & $0.385^{* * *}$ & $0.245^{* *}$ & & & \\
\hline Traumatic Stress & & & & & $0.271^{* *}$ & \\
\hline$R^{2}$ Adjust & 0.784 & 0.636 & 0.767 & 0.276 & 0.510 & 0.436 \\
\hline
\end{tabular}

${ }^{* *} p<0.01 ; * p<0.05 ; * * * p<0.001$.

\section{Discussion}

Results showed that patients and partners displayed symptoms of anxiety, depression and traumatic stress symptoms. In fact, cancer is considered one of the most feared illnesses in the general population causing several emotional reactions (Murard, 1996; Figueiredo et al., 2001; Santos, 2003). Cancer affects the partner, since it requires a change in the couple's organization of daily life and interpersonal relationships (Wagner and Cella, 2004).

Results are in accordance with the literature showing patients, who experienced surgery, and their partners, to have lower levels of traumatic stress and psychological morbidity when compared to the other two groups. In fact, patients who experienced surgery/ chemotherapy and surgery/radiotherapy have more treatment side effects and, as a result, more suffering, more trips to the hospital and more periods of in patient treatment than surgical patients and these factors may have contributed to more psychological morbidity (Denlinger and Barsevick, 2009). Surgical patients showed only minor levels of anxiety, depression and posttraumatic stress symptoms. Although not significant, depression and post-traumatic stress were higher in patient who received chemotherapy versus radiotherapy indicating that these patients may be more at psychological risk.

Cancer patients are different from other individuals who experienced other types of trauma i.e. singular events that have stopped. Cancer patients, on the other hand, since their ongoing medical follow-up visits, are surrounded by the realistic fear of disease's recurrence and other medical problems or hospitalization (Duhamel et al., 2000). Given these unavoidable, recurrent exposures to these trauma related triggers, it comes as no surprise that cancer patients who received chemotherapy or radiotherapy perceive their cancer as more severe and, as a result, showed more traumatic stress symptoms.

Patients who received a diagnosis longer than a year showed more traumatic stress symptoms since the threat for recurrence becomes more real. According to literature, newly diagnosed patients with cancer often respond more with sadness, anxiety or develop depression (Bush, 2008). Traumatic stress, on the other hand, requires a longer course of illness. In fact, research shows that only $3 \%-4 \%$ of patients with early-stage cancer meet full PTSD criteria, but it gets as high as $35 \%$ in patients evaluated after treatment (NCI, 2009). On the other hand, $20 \%$ of cancer survivors with early-stage disease and $80 \%$ of patients diagnosed with recurrence may have "partial" PTSD symptoms (Knobf, 2007; Shelby et al., 2008).

Lower levels of traumatic stress, anxiety and depression were reported in surgical patients compared to the other two groups. In surgical patients, PTSD-associated symptoms may be related to the trauma itself and/or surgical intervention. Experiences due to treatment in the ICU, such as pain, lack of control and inability to express needs were predictors of psychological distress symptoms a short time after ICU discharge (Myhren et al., 2009). However, in radiotherapy and chemotherapy patients have even less control over treatments and that fact together with a severe subjective appraisal of their cancer may explain why traumatic stress symptoms are higher in these two groups.

In partners, differences were found in anxiety state and posttraumatic stress i.e. partners of patients who went through surgery when compared with the other two groups showed less anxiety and traumatic stress. These results may be due to treatment' side effects that are less intense in surgery and, therefore, have a lower impact in the partner (Bartelink et al., 2002) as well.

Depression was the only significant variable correlated in patients and partners. These results are in accordance with some literature that has shown partners to have higher anxiety than cancer patients but did not differ on depressive symptoms (Manne et al., 2003). Partners' anxiety has also been associated to depression and fatigue in patients with breast cancer (Segrin et al., 2007). In fact, studies have shown an association between patient and partners' distress i.e. partners' distress reactions are closely linked to patients. The close relationship found between patient and partners' depression provides some support for the concept of "couples at risk", defined as a pattern of high-high distress in both partners (Keller et al., 1996). This result is interesting because highlights the importance of psychological intervention, after cancer treatment, besides the initial phase of diagnosis. Therefore, early identification of high-risk couples is critical. Psychological interventions designed to help cancer patients reduce their depression may ultimately contribute to reduce partners' depression that compromise their ability to provide the needed support that would help the patient to adjust better to treatment.

Anxiety and depression were significant predictors of quality of life. In fact, cancer treatment (surgery, chemotherapy, radiotherapy), with its collateral side effects produce physical and emotional disturbances that influence quality of life (Holland et al., 1986; Hacpille, 2000). Interestingly, anxiety and traumatic stress symptoms predicted symptom distress - pain/bowel pattern and this is the only dimension of quality of life predicted by traumatic symptoms. This result may have to do with colon pain that patients may feel directly related to less quality of life since pain impacts patients' daily activities and, as a result, may be related to traumatic symptoms (Couvreur, 2001). Also, traumatic symptoms may be associated to fears of mutilation and a consequent uncertain future due to the possible need of an ostomy.

In conclusion, this study highlights the importance of providing psychological interventions for cancer patients and their partners. Chemotherapy patients and those diagnosed over a year are more at risk.

\section{Limitations}

The use of self reported measures, the fact that patients were all recruited in one institution and the small number of partners limit the generalization of these findings.

Future studies should determine how patients and partners' illness representations relate to traumatic stress symptoms and 
psychological morbidity as well as whether burden may be a mediator in the relationship between psychological morbidity, (in partners), and quality in life (in patients). It will be also important to include illness stage, coping mechanisms and previous experience of trauma as moderating factors.

Finally, it would be important to study the impact of patients and partners' gender and age on psychological morbidity controlling for disease relapse.

\section{Conclusion}

The present study revealed differences in colorectal patients and their partners in psychological morbidity according to different types of treatment. According to results, patients who received chemotherapy are more at risk than the other two groups.

Psychiatric symptoms ranging from anxiety and depression to PTSD can interfere with patient functioning, including compliance with oncologic treatments and follow-up examinations, family and social relationships, and occupational roles. As a result, greater understanding of factors that may predict cancer-specific distress could enable better clinical or psychoeducational interventions.

Educating the patient and family regarding diagnosis and treatment is invaluable. Hospitals should provide interventions to help patients and partners adapt to cancer and go through the illness' stages in order to promote their quality of life. Health professionals should also be attuned for signs of clinical distress and screen patients and partners who are most in need of psychological help. For some patients and partners, psychotherapy may be necessary and should be one of the options available.

\section{Conflict of Interest Statement}

No conflict of Interest declared.

\section{References}

Andrykowski, A., Cordova, J., 1998. Factors associated with PTSD symptoms following treatment for breast cancer: test of the Andersen model. Journal of Traumatic Stress 11, 189-203.

Badger, T., Segrin, C., Dorros, S.M., Meek, P., Lopez, A.M., 2007. Depression and anxiety in women with breast cancer and their partners. Nursing Research 56 (1), 44-53.

Bartelink, H., Schellens, J.H.M., Verheij, M., 2002. The combined use of radiotherapy and chemotherapy in the treatment of solid tumors. European Journal of Cancer 30 (2), 216-222.

Beck, A., Mendelson, M., Moch, 1961. An inventory for measuring depression. Archives of General Psychiatry, 561-571.

Belcher, A., 1996. Enfermería y cáncer. Mosby/Doyma Libros, Barcelona.

Bishop, G., 1994. Health Psychology: Integrating Mind and Body. Allyn and Bacon, Boston.

Blanchard, C., Albrecht, T., Uckdeschel, J., 1997. The crisis of cancer: psychological impact on family partners. Oncology $11,189-194$

Bush, N.J., 2008. Depression and anxiety. In: Chernecky, C., Ende, K. (Eds.), Acute Care Oncology Nursing. Saunders, Philadelphia, pp. 97-110.

Couvreur, C., 2001. A Qualidade de Vida: Arte para Viver no Século XXI. Lusociência, Loures. 53-91.

Creamer, M., Bell, R., Failla, S., 2003. Psychometric properties of the impact of event scale-revised. Behaviour Research and Therapy 41, 1489-1496.

Demetri, G., 2001. Anemia and its functional consequences in cancer patients: current challenges in management and prospects for improving therapy. British Journal Cancer 84 (1), 17-23.

Denlinger, C.S., Barsevick, A.M., 2009. The challenges of colorectal cancer survivorship. Journal of the National Comprehensive Cancer Network 7 (9) 883-894.

Duhamel, K.N., Ostroff, J.S., Bovbjerg, D.H., Pfeffer, M., Morasco, B.J., Papadopoulos, E., et al., 2000. Trauma-focused intervention after bone marrow transplantation: a case study. Behavior Therapy 30 (1), 175-186.

Figueiredo, A., Ferreira, L., Figueiredo, P., 2001. Impacto psico-social do cancro da mama na mulher. Enfermagem Oncológica 17, 22-27.

Ganzl, R., 1996. Cancer colorretal. In: Murard, A., Katz, A. (Eds.), Oncologia. Bases Clínicas do Tratamento. Guanabara Koogan, Rio de Janeiro, pp. 176-179.

Gaecia, I., Wax, P., Ghwrtzmann, F., 1996. Aspectos psicossociais do paciente com câncer. In: Murard, A., Katz, A. (Eds.), Bases Clinicas do Tratamento. Guanabara Koogan, Rio de Janeiro, pp. 125-131.
Hacpille, L., 2000. A Dor Cancerosa e seu Tratamento. Abordagem em Cuidados Paliativos. Instituto Piaget, Lisboa.

Hann, D., Jacobsen, P., Martin, S., Azzarela, L., Grenberg, H., 1998. Fatigue and quality of life following radiotherapy for breast cancer. a comparative study. Journal of Clinical Psychology in Medical Setting 5 (1), 19-33.

Holland, J., Silberfarb, P., Tross, S., Celia, D., 1986. Psychosocial research in cancer: the cancer and Leukemia group B. In: Ventafridda, V. (Ed.), Assessment of Quality of Life in Cancer Treatment. Experta Medica, pp. 89-101.

Hurter, B., Bush, N., 2007. Cancer-related anemia: clinical review and management update. Clinical Journal Oncology Nursing 11, 349-359.

Imbembo, A., Lefour, A., 1993. Carcinoma do cólon, do recto e do ânus. In: Sabiston, A. (Ed.), Tratado de Surgery. As bases biológicas da prática cirúrgica moderna, pp. 892-905.

Keller, M., Henrich, G., Sellschopp, A., Beutel, M., 1996. Between distress and support: Spouses of cancer patients. In: Baider, L., Cooper, C.L., Kaplan DeNour, A. (Eds.), Cancer and the Family. Wiley, New York, pp. 187-224.

Knobf, M.T., 2007. Psychosocial responses in breast cancer survivors. Seminars in Oncology Nursing 23 (1), 71-83.

Lopes, M., 1997. A integração do doente oncológico no seu meio bio-sócio-familiar: Problemas mais frequentes no doente oncológico pós-alta. Revista- Enfermagem em foco VII, 28.

Maguire, P., 1994. Abc of breast diseases. Psicological aspects. British Medical Journal 309, 1649-1652.

McCray, N., 2000. Questões psicossociais e da qualidade de vida. In: Otto, S. (Ed.), Enfermagem em Oncologial. Lusociência, pp. 893-912.

Maden, J., 2006. The problem of distress in patients with cancer. More effective assessment. Clinical Journal Oncology Nursing 10 (5), 615-619.

Manne, S., Ostroff, J., Sherman, M., Glassman, M., Ross, S., Goldstein, L.F.K., 2003. Buffering effects of family and friend support on associations between partner unsupportive behaviors and coping among women with breast cancer. Journal of Social and Personal Relationships 20 (6), 771-792.

McIntyre, T., McIntyre, S., 1995a. Beck Depression Inventory (BDI). Research Version. University of Minho, Braga, Portugal.

McIntyre, T., McIntyre, S., 1995b. State Trait Anxiety Inventory (STAI). Research Version. University of Minho, Braga, Portugal.

Murard, A., 1996. Câncer Ana. In: Murard, A., Katz, A. (Eds.), Oncologia. Bases Clínicas do Tratamento. Guanabara Koogan, Rio de Janeiro, pp. 180-181.

Murphy, M., 2000. Cancro colorrectal. In: Otto, S. (Ed.), Enfermagem em oncologia. Lusociência, Loures, pp. 137-154.

Myhren, H., Toien, K., Ekeberg, O., Karlsson, S., Sandvik, L., Stokland, O., 2010. Posttraumatic stress, anxiety and depression symptoms in patients during the first year post intensive care unit discharge. Critical Care 14 (1), R14.

National Cancer Institute, 2009. Post-Traumatic Stress Disorder. Retrieved March 30, 2009, from. www.cancer.gov/cancertopics/pdq/supportivecare/posttraumatic-stress/patient.

Nicolussi, A., Sawada, N., 2009. Quality of Life of patients with colorectal câncer who were receiving complementary therapy. Acta Paulista de Enfermagem 22 (2), 155-161.

Nunnally, J.C., 1978. Psychometric Theory, second ed. McGraw-Hill, New York.

Padilla, G.V., Presant, C., Grant, M.M., Metter, G, Lipsett, J, Heide, F, 1983. Quality of life index for patients with cancer. Research Nursing Health 6 (3), 117-126.

Pandey, M., Sarita, G.P., Devi, N., Thomas, B., Hussain, B.M., Krishnam, R., 2006. Distress, anxiety, and depression in cancer patients undergoing chemotherapy. World Journal of Surgical Oncology 4, 68.

Passik, S., Grummon, L., 1998. Post traumatic stress disorder. In: Holland, J. (Ed.), Handbook of Psychoncology. Oxford University Press, New York, pp. 595-607.

Pereira, M., Lopes, C., 2002. O doente oncológico e sua família. Climepsi, Lisboa.

Pereira, M.G., Figueiredo, A.P., 2008. Depressão, Ansiedade e Stress Pós-Ttraumático em Doentes com Cancro Colo-rectal: Validação do Hospital Anxiety and Depression Scale (HADS) e Impact of Events Scale-R numa amostra de doentes oncológicos. Onco News 5, 10-19.

Pereira, M., Figueiredo, A., 2005. Quality of Life Scale-Cancer (QOL-CA). Versão de Investigação. Universidade do Minho, Braga, Portugal.

Perez, S., Galdón, M., 2002. Transtorno de estrés postraumático de câncer. In: Dias, M., Durá, E. (Eds.), Territórios da Psicologia Oncológica. Climepsi, Lisboa, pp. 493-526.

Pollack, J., Holm, T., Cedermark, B., Attman, D., Holmstroim, B., Glimelious, B., Melgree, A., 2006. Late adverse effects of short-course preoperative radiotherapy in rectal cancer. British Journal of Surgery 93 (12), 1519-1525.

Pontes, L., 2005. Registo Oncológico Nacional. Instituto Portugûes de Oncologia, Porto.

Potash, M., Breibart, W., 2002. Affective disorders in advanced cancer. Clinic North American., 671-700.

Roth, A., Breitbart, W., 2001. Principles of psychosocial oncology. In: Rubin, P. (Ed.), Clinical Oncology: A Multidisciplinary Approach for Physician and Students, New York, pp. 220-238.

Santos, C., 1999. Saúde e qualidade de vida da pessoa portadora de Ostomia de Eliminação. Master Thesis, Faculty of Psychology and Educational Sciences, Oporto.

Santos, C., 2003. Representação cognitiva e emocional, estratégias de coping e qualidade de vida no doente oncológico e família. Doctoral Dissertation, Faculty of Psychology and Educational Sciences, Oporto University.

Santos, Z., 1995. Reacções emocionais e apoio psicológico ao doente com doença grave. Cuidar 2, 3-7. 
Schmidt, C.E., Bestmann, B., Kuchler, T., Longo, W.E., Kremer, B., 2005. Ten year historic cohort of quality of life and sexuality in patients with rectal cancer Diseases of Colon and Rectum 48 (3), 483-492.

Segrin, C., Badger, T., Dorros, S.M., Meek, P., Lopez, A.M., 2007. Interdependent anxiety and psychological distress in women with breast cancer and their partners. Psycho-Oncology 16 (7), 634-643.

Shelby, R.A., Golden-Kreutz, D.M., Andersen, B.L., 2008. PTSD diagnoses, subsyndromal symptoms, and comorbidities contribute to impairments for breast cancer survivors. Journal of Traumatic Stress 21 (2), 165-172.

Smith, R., Tchekmedyian, S., 2002. Practitioners practical model for managing cancer-related anemia. Oncology 16 (Suppl 10), 55-63.

Singer, S., Kuhnt, S., Götze, H., Hauss, J., Hinz, A., Liebmann, A., et al., 2009. Hospital anxiety and depression scale cutoff scores for cancer patients in acute care. British Journal of Cancer 100, 908-912 (2009).

Spielberger, C., Gorsuch, R., Lushene, R., Vagg, P., Jacobs, G., 1983. Manual for the State-Trait Anxiety Inventory, (FormY), Self Evaluation Questionnaire. Consulting Psychologists Press, Inc.
Wagner, L., Cella, D., 2004. Fatigue and cancer: causes, prevalence and treatment approaches. British Journal Cancer, 822-828.

Weihs, K., Reiss, D., 1996. Family reorganization in response to cancer: a developmental perspective. In: Baider, L., Cooper, C., De-Nour, A. (Eds.), Cancer and Family. Wiley \& Sons, Chichester, pp. 3-29.

Weiss, D., Marmer, C., 1977. The Impact of Event Scale - Revised. In: Wilson, J. Teane (Eds.), Assessing Psychological Trauma and PTSD. Guildford, New York.

Weitzner, M.A., McMillan, S.C., Jacobsen, P.B., 1999. Family caregiver quality of life: Differences between curative and palliative cancer treatment settings. Journal of Pain and Symptom Management 17 (6), 418-428.

Yost, K.J., Hahn, E.A., Zaslavsky, A.M., Ayanian, J.Z., West, D.W., 2008. Predictors of health-related quality of life in patients with colorectal cancer. Health and Quality of Life Outcomes 6, 66.

Zabora, J., Brintzenhofeszoc, K., Curbow, B., Hooker, C., Piantadosi, S., 2001. The prevalence of psychological distress by cancer site. Psycho-Oncology 10 (1), 19-28.

Zigmond, A.S., Snaith, R.P., 1983. The Hospital Anxiety and Depression Scale. Acta Psychiatric Scandinavia 67 (6), 361-370. 